\title{
Clinical Simulation in pediatrics and neonatology using EDISON: an educational innovation project
}

Evelin Balaguer-López ${ }^{1}$, Pablo García-Molina ${ }^{1}$, José María Blasco², Enrique SanchisSánchez $^{2}$, Pablo Buck-Sainz-Rozas ${ }^{1}$, Pedro García-Martínez ${ }^{1}$, Manuel Ruescas-Pérez ${ }^{1}$ ${ }^{1}$ Department of Nursing, University of Valencia, Spain, ${ }^{2}$ Department of Physiotherapy, University of Valencia, Spain.

\begin{abstract}
Introduction: Clinical simulation is a tool that allows creating controlled and safe spaces that mimic reality, where students can acquire skills and abilities prior to facing real situations.

Methodology: This is a two-phases study. The first quasi-experimental phase where 3 questionnaires were used; two of them to assess knowledge (pretest posttest) and the other one to assess the satisfaction of the training action. The second phase was analytical, where the effectiveness of a training intervention in a confinement context based on the use of audiovisual materials created through EDISON was evaluated.

Results: In 2019 the average satisfaction of the students was 9.22 (SD 0.72) out of 10. The most valued item was the one related to the domain that the instructors had regarding the knowledge imparted, showing 9.79 out of 10. The students' knowledge improved in 9 of the 11 questions.

Conclusions: The satisfaction of the students and the knowledge acquired were remarkable, being clinical simulation a methodology that helps to consolidate the knowledge and skills put into practice.
\end{abstract}

Keywords: Cardiopulmonary resuscitation; pediatrics; clinical simulation; university teaching; educational innovation. 


\section{Introduction}

The Educational Innovation program in basic and advanced Cardiopulmonary Resuscitation in pediatrics and neonatology in a realistic context is included within the subject "Nursing in Child and Adolescent Health" (NCAH), taught in the 2nd year of the Bachelor's degree in Nursing at the Faculty of Nursing and Podiatry (FNP) of the University of Valencia. It is part of a project on Educational Innovation and Improvement of teaching quality (Uv.es, 2017).

In this educational program taught in the 2018/2019 academic year, several clinical situations of the pediatric and neonatal critical context were designed, in which the students of the $\mathrm{NCAH}$ subject had to face various scenarios where they could dynamically implement the knowledge, skills and attitudes acquired throughout the academic year.

In order to make decisions, students must be previously exposed to clinical situations where they can discuss possible solutions. For this reason, the incorporation of clinical simulation in nursing teaching is important, since in this way the future professional will be able to face effectively the complex and changing dilemmas that will arise throughout their practice. professional, and thus improving the quality and safety of patient care (Tortajada-Lohaces, et al., 2018).

Nursing teachers cannot expect their students to learn to solve situations in their future daily practice, only through the observation of the teacher or "passive" documents based on presentations. Students must be exposed to clinical situations where they can discuss possible solutions, to later make decisions. Therefore, it is important to incorporate clinical simulation together with 3D environment tools in nursing teaching (Guimond, et al., 2011; Urra, et al. 2017).

This type of teaching methodology is important for training in the proper management of an emergency situation, since it is very difficult to train and evaluate during the real emergency. When a critical situation occurs there is no time to stop and think about what the next step will be, for this reason it is essential to practice the action protocol, to know what actions to carry out. And the only way to practice an emergency situation without endangering the patient's life is through a realistic environment generated in $3 \mathrm{D}$ when we are in a confinement situation (De la Horra, 2010). The fact that students in more advanced courses use the EDISON tool to deal with topics such as pediatric and neonatal CPR (coordinated by specialist health professionals) will allow them to provide them with the essential skills to be the ones who train the 2nd year course students themselves.

\section{Aims}

1. All 2nd year nursing students must know how to correctly perform CPR in children after the Infant and Adolescent Health Nursing course. 
2. To strengthen the knowledge about pediatric CPR of all 2nd grade students and also enhance the knowledge of 3rd and 4th grade students who participate as monitors.

3. To ass the knowledge about pediatric CPR before and after the educational intervention (simulation and EDISON online), as well as student satisfaction with this teaching methodology.

\section{Metodology}

This Teaching Innovation Project (TIP) designed in two phases was accepted by the "ViceRectorat d'Ocupació i Programes Formatius" of the University of Valencia in 2019 to be carried out in two academic years 2019-2021, which the project code is UV-SFPIE_PID191096189 and a founding of 1000 euros.

\subsection{First Phase}

In the first phase, the methodology of previous years was followed (García-Molina et al., 2019, 2018), being a quasi-experimental study (not controlled), in which three questionnaires were used (pre-test and post-test knowledge; satisfaction) of evaluation as a method to collect the information regarding the acquisition of competences and student satisfaction in relation to the simulation.

The questionnaire to assess satisfaction was anonymous and consisted of 20 items, which had to be scored from $0-10$ according to the degree of satisfaction that students had in this regard, being $0 / 10$ the "lowest degree of satisfaction" and being 10/10 the "degree highest satisfaction".

In this way, different aspects related to the laboratory were evaluated: usefulness of the laboratory, methodology, organization and resources, teaching team and general evaluation.

On the other hand, the evaluation of knowledge was carried out using two tests: one before starting the laboratory (pre-test) and the other one at the end (post-test). Both questionnaires, like the satisfaction questionnaire, were anonymous, and contained 11 questions. The format was multiple-choice questions, in which only one answer was correct. The order of the questions in the post-test was different from the order of the questions in the pre-test.

To develop this phase of the project, in the academic year 2018-2019, 18 CPR simulation laboratories of 2 hours duration were carried out, in which 160 students of the 2 nd year of the subject NCAH participated. In addition, 6 students of 3rd and 4th year of the Nursing degree and 13 nurses participated as monitors of the simulation.

Prior to the simulation laboratories, a theoretical class on pediatric CPR was given to the 2nd year students and, from April 8 to May 10, 2019, the simulation laboratories were carried out. Approximately 152 nd year students participated in each laboratory and 3 clinical cases 
were carried out in which the scenario created for this purpose was that of a subway accident where there were multiple victims.

Each case was tutored by a member of the innovation group, the distribution being:

1. Advanced CPR on a 2-year-old pediatric patient: NCAH professor.

2. CPR instrumentalized in premature newborn: 3rd or 4th grade student assigned to innovation.

3. Basic CPR in a 2-month-old infant: 3rd or 4th grade student assigned to innovation.

4. Evaluation of tutors: faculty professor assigned to innovation.

The monitor/tutor in each case was responsable of evaluating the students' intervention. The external evaluator was responsable of evaluating both the 2 nd grade students and the monitor/tutors assigned to the innovation through a check-list, and at the end of the laboratory an analysis of the evaluation was carried out as a whole (debriefing).

\subsection{Second phase}

The second phase of the study, in the 2019-2020 academic year, was influenced by the COVID-19 confinement. The innovation staff redesigned the methodology for this second phase. Simulated demonstration videos on CPR techniques were provided, previously recorded and edited by the teaching team of the subject. In addition, both supporting documentation and videoconferences were offered synchronously, and all 2nd year students were allowed to record the class. These classes were offered by 4 th year students, tutored by a teacher of the subject. These didactic resources were offered to all students.

In order to assess the value of applying attractive virtual environments created using EDISON in CPR education, audiovisual materials organized as a "video book" were created (an exemple in https://mmedia.uv.es/html5/u/pa/pagarmo3/61706_06_soporte_vital_avanzado_pediatrico_iii.mp4). This option can be found in the "AulaVirtual" (based on the MOODLE environment). "Edison" (https://www.brainstorm3d.com/products/edison/) is an interactive tool for creating presentations that increases the attention of students and helps the transmission of the message by immersing the teacher in their presentation in a $3 \mathrm{D}$ environment. It is a templatebased application that allows teachers to transform the learning process by seeking to create a different educational experience, which allows both students and teachers to interact with augmented reality graphics immersed in customizable virtual environments and complete the lessons with predefined 3D elements. The teachers were able to explain complicated concepts in a simple, visual and practical way. Once the template is loaded, the program inserts the teacher, captured by the laptop's camera, into the augmented reality scene, which can be customized using the different resources and objects available. 
As the video book was made in Spanish, it was decided to use it in the groups where Spanish was the language used in the classes and teaching materials. 2 groups (Spanish) were taught in the Virtual Classroom with a video book (WVB), while other 3 groups (Valencian) had not a video book (NVB), using the rest of the resources that the other 2 groups also had. The effectiveness of the video book was measured through the questions on CPR that were formulated in the final exam for the subject in June 2020. The same 10 questions were asked to all students within a 55-question exam. They were assessed whether there were significant differences between the groups, both in the 10 questions on CPR, and in the entire examination. The satisfaction of the student was not evaluated as in the first phase.

\section{Results}

In the first phase, the results of the satisfaction survey are reflected in Figure 1, where the score for each of the items appears. The average grade awarded by the 160 respondents is 9.22 (SD 0.72) out of 10. The item most valued by the students was 16 (mastery of the contents taught by the teacher) showing a result of 9.79 out of 10 . On the other hand, the item showing the lowest score was question number 11 , which refers to whether the physical facilities facilitated the development of the laboratory, showing a result of 8.49 out of 10 .

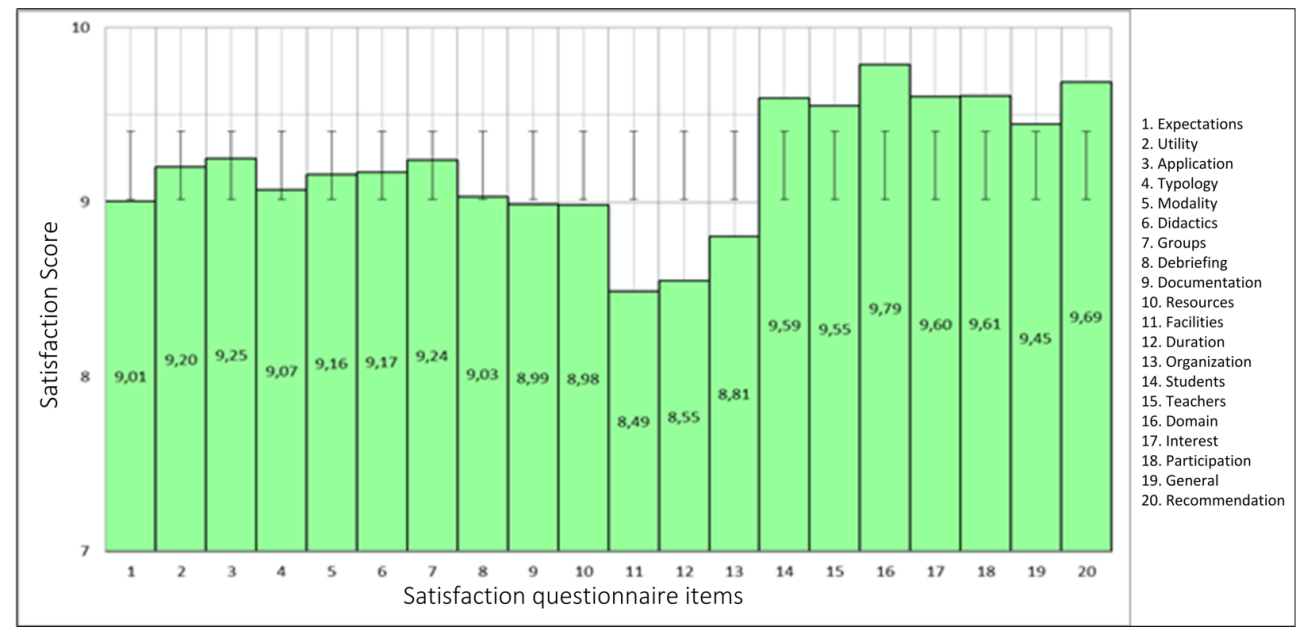

Figure 1. Satisfaction survey results. Source: own elaboration.

Regarding the results obtained in the pre-test and the post-test, which are shown in figure 2 and 3, which show the percentage of correct answers and mistakes in each of the questions. 


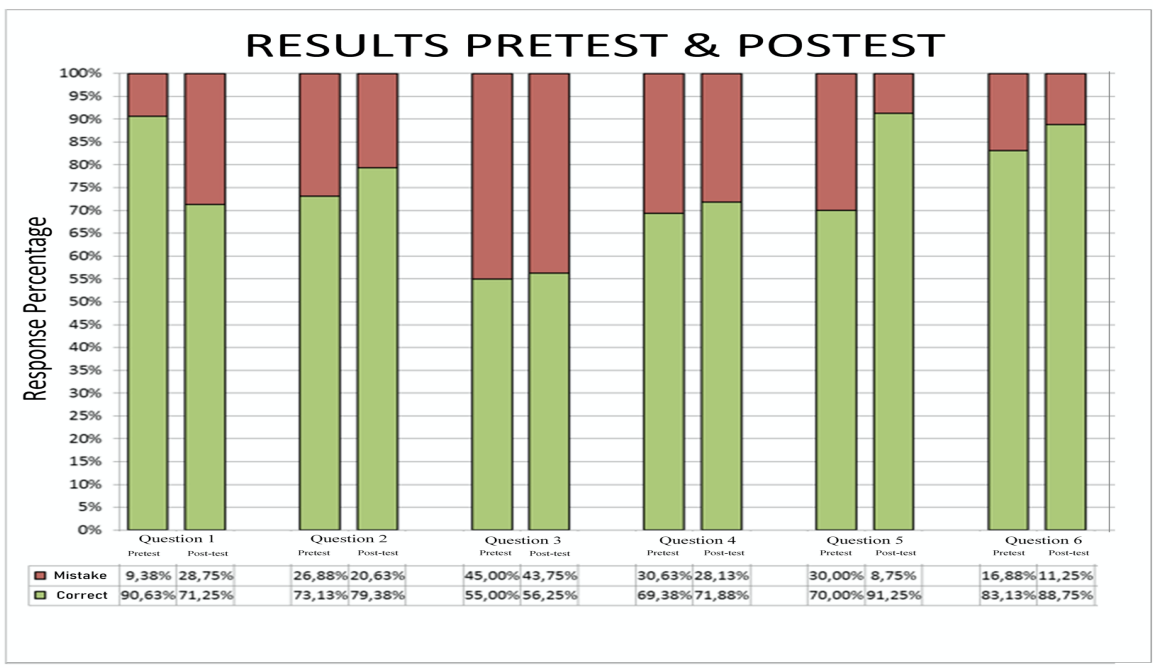

Figure 2. Pre-test vs post-test results. First 6 questions. Source: own elaboration.

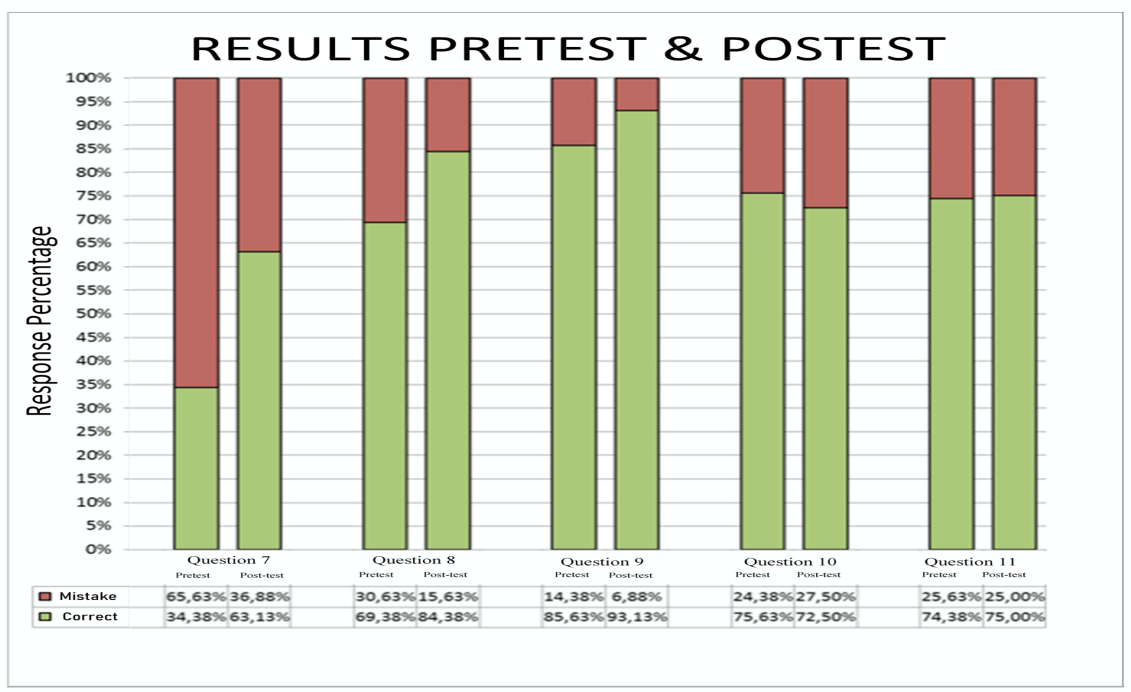

Figure 3. Pre-test vs post-test results. 5 questions until 11 questions. Source: own elaboration.

On average, the students improved their knowledge in 9 of the 11 questions. The question that received the most correct answers from the pre-test was question number 1 (compression-ventilation ratio in children under 2 years of age), in which $90.63 \%$ (145 people) of the students were correct. Instead, the question showing the least correct answers in the pretest was question 7 (intubation time), which was correct by $34.38 \%$ (55) of the students. However, this question was the one in which the most improvement occurred, 
raising the percentage of correct answers to $63.13 \%$ (101) corresponding to question 10 of the post-test.

Regarding the post-test, the question showing the most correct answers was question 4 of the post-test (no. 9 of the pre-test) (frequency to reassess a 6-year-old girl during CPR) showing a percentage of correctness of $93.13 \%$ (149). And the question showing the fewest correct answers in the post-test was question number 5 (chest compression depth in a 5-year-old child), this question was correct by $56.25 \%$ (90), showing a minimal variation with respect to its counterpart in the pre-test (question 3) in which the percentage of correct answers was $55 \%(80)$.

296 students participated in the second phase of the project. $37.8 \%$ (112) of the students received WVB training. The final average mark of the 55-question exam was 8.44 (SD 0.55) for the WVB group, while it was 8.62 (SD 0.54) for the NVB group.

There are significant differences $(\mathrm{p}<0.00)$ in the numerical grades obtained between WVB students and NVB students, the numerical mean of SVL students being higher. However, when transferring these numerical scores to the categorical rating, the WVB students obtained a higher percentage of the rating of Excellent and Notable ( $99.11 \%$ of the ratings) than the NVB students $(98.65 \%$ ) without differences significant (Table 1).

Table 1. Distribution of evaluation between the group with a Videbook and without a Videobook.

\begin{tabular}{lccc}
\hline Label & CVL & SVL & Total general \\
\hline Good (6-6.9) & $1(0.89 \%)$ & $3(1.63 \%)$ & $4(1.35 \%)$ \\
Remarkable (7-8.9) & $10(8.93 \%)$ & $19(10.33 \%)$ & $29(9.80 \%)$ \\
Excellent (9-10) & $101(90.18 \%)$ & $162(88.04 \%)$ & $263(88.85 \%)$ \\
Total general & 112 & 184 & 296 \\
\hline \multicolumn{4}{c}{ Source: Own elaboration. }
\end{tabular}

When evaluating in which questions there were significant differences in the score obtained, it is observed (Table 2) that question 31 obtains a lower mean score in the WVB group than in the NVB group.

Table 2. Questions of the 10 evaluation items with relevant differences.

\begin{tabular}{lccc}
\hline CPR questionnaire questions & WVB & NVB & p \\
\hline Compression-ventilation relationship in CPR & 0.1982 & 0.1913 & 0.05 \\
CPR medication administration guideline 1 & 0.1946 & 0.1804 & 0.08 \\
CPR medication administration guideline 2 & 0.1054 & 0.1478 & 0.00 \\
CPR medication administration guideline 3 & 0.1964 & 0.1859 & 0.02 \\
\hline \multicolumn{2}{c}{ Source: Own elaboration } \\
\hline
\end{tabular}

Source: Own elaboration. 
The rest of the questions of the evaluation questionnaire did not obtain significant differences in the mean score obtained between both groups.

The innovation staff considers that using Video Books will improve the quality of teaching in the groups where they will be included. However, it is true that the form of evaluation through online exam questions was not ideal in order to fully evaluate the tool. It would have been engaging to carry out a qualitative assessment of the results through interviews with the students of both groups (with and without Videobooks).

Moreover, authours suggest designing a specific questionnaire in order to evaluate the effectiveness of specific training interventions (such as video books), and not only through questions in the final exam of the subject.

\section{Conclusions}

Clinical simulation helps to enhance and consolidate the knowledge and skills in the field of Basic and Advanced Pediatric and Neonatal Life Support.

The satisfaction of the students and the knowledge acquired were remarkable. To improve their satisfaction, it is mandatory to adapt the physical space where the simulation laboratories are carried out and modify the simulation times.

Using Videobooks the application of the Inverted Classroom methodology and the creation of realistic scenarios in a context of home confinement is useful. EDISON is a useful tool for the application of the Inverted Classroom methodology and the creation of realistic scenarios in a context of home confinement. However, adjustments are required to the Videobooks to enhance the digital experience and thus the assessment of CPR knowledge.

\section{References}

De la Horra Gutiérrez, I. (2010). La simulación clínica como herramienta de evaluación de competencias en la formación enfermera. Reduca. Universidad Complutense de Madrid.

Figueroa, A. A. (1999). La innovación en la educación superior en enfermería y los aportes del diseño de instrucción. Revista Latino-Americana de Enfermagem, 7(2), 5-13. https://doi.org/10.1590/S0104-11691999000200002

Guimond, M., Sole, M., \& Salas, E. (2011). Getting ready for simulation- based training: A checklist for nurse educators. Nurs Educ Perspect, 32(3), 179-185.

Tortajada-Lohaces, A. (2018). Innovación educativa en Reanimación Cardiopulmonar Básica y Avanzada en pediatría y neonatología en un contexto realista. Departanmento de Enfermería. Universidad de Valencia.

Urra Medina, E., Sandoval Barrientos, S., \& Irribarren Navarro, F. (2017). El desafío y futuro de la simulación como estrategia de enseñanza en enfermería. Investigación en Educación Médica, 6(22), 119-125. https://doi.org/10.1016/j.riem.2017.01.147 
Uv.es. (2017). Convocatoria de proyectos de innovación educativa y mejora de la calidad docente, curso 2017/18. 